\title{
O MEIO AMBIENTE NATURAL E A PROTEÇÃO INTEGRAL DAS CRIANÇAS: A EDUCAÇÃO AMBIENTAL COMO DEVER FUNDAMENTAL DOS PAIS PARA A PRESERVAÇÃO DAS PRESENTE E FUTURAS GERAÇÕES
}

\author{
Daury Cesar Fabriz ${ }^{1}$ \\ Heleno Florindo da Silva ${ }^{2}$
}

\begin{abstract}
Resumo
A presente pesquisa objetivou, entre outros aspectos, analisar os deveres fundamentais a partir da compreensão, num primeiro momento, do conceito de dever fundamental, para, a partir de então, desenvolver a análise do dever fundamental de proteção ao meio ambiente natural, bem como do dever dos pais de proteção integral e prioritária de seus filhos, sobretudo das crianças e, por fim, da educação ambiental como instrumento de efetivação desses deveres. Ou seja, de como a educação ambiental pode ser compreendida como parte do dever fundamental dos pais em garantir um crescimento sadio e harmonioso em sociedade ao seus filhos, destacando-se, assim, como um mecanismo de preservação não somente do meio ambiente natural, mas, principalmente, de proteção integral e prioritária das crianças, do presente, bem como, das futuras gerações.
\end{abstract}

Palavras-chave: Meio Ambiente Natural; Proteção Integral e Prioritária; Deveres Fundamentais; Pais; Crianças.

\section{INTRODUÇÃO}

A atualidade dos seres humanos os obriga a identificar e realizar atos, das mais variadas espécies e naturezas, sempre ao mesmo tempo, instantaneamente, pois o Homem de hoje - o aceito social, cultural e politicamente pela sociedade em que vive - é aquele que consegue acompanhar todo o cenário de virtualização das relações humanas, de patrimonialização dos padrões sociais e de conflito entre os papeis sociais desenvolvidos individual e coletivamente por todos.

\footnotetext{
${ }^{1}$ Doutor em Direito pela Universidade Federal de Minas Gerais. Coordenador do Programa de Pós-Graduação Stritu Sensu em Direitos e Garantias Fundamentais (Mestrado) da Faculdade de Direito de Vitória. Coordenador do Grupo de Pesquisa Estado, Democracia Constitucional e Direitos Fundamentais. Presidente da Academia Brasileira de Direitos Humanos (ABDH). E-mail daury@terra.com.br.

${ }^{2}$ Doutorando em Direitos e Garantias Fundamentais pela Faculdade de Direito de Vitória (FDV). Membro do Grupo de Pesquisa Estado, Democracia Constitucional e Direitos Fundamentais da Faculdade de Direito de Vitória (FDV). Membro Diretor da Academia Brasileira de Direitos Humanos (ABDH). Professor no Curso de Direito da Faculdade Multivix Cariacica. Coordenador Geral do Curso de Direito da Faculdade Multivix Cariacica. Professor do Centro de Evolução Profissional (CEP). Email: hfsilva16@hotmail.com
} 
É a partir desse contexto que o trabalho busca analisar os problemas inerentes ao debate acerca do meio ambiente natural $^{3}$, principalmente, discussões acerca dos deveres fundamentais de proteção desse meio ambiente, bem como de proteção integral e prioritárias das crianças à luz da atuação dos pais como mecanismo de educação ambiental para proteção das futuras gerações.

Para tanto, num primeiro momento, abordou-se acepções básicas sobre a ideia de deveres fundamentais, vistos aqui partir de uma construção múltiplo-dialética, o que possibilitou, ao final, apresentar um conceito de dever fundamental construído pelo Grupo de Pesquisa Estado, Democracia e Direitos Fundamentais.

A seguir, buscou-se trazer às discussões a inter-relação entre o dever fundamental de proteção ao meio ambiente natural e o dever fundamental dos pais em proteger prioritariamente e integralmente seus filhos, construindo, a partir daí, a ideia de um dever fundamental dos pais em possibilitar uma educação ambiental a seus filhos, o que foi visto como um importante instrumento de proteção tanto do meio ambiente, como das futuras gerações.

Partindo dessas premissas, sobretudo da ideia de que a proteção do meio ambiente natural é um dever imposto pela Constituição Federal de 1988 não só ao Estado, mas, também, a toda a sociedade - onde se incluem, principalmente, o núcleo familiar - que, através de um diálogo múltiplo dialético, buscou-se resposta ao seguinte problema de pesquisa: é possível visualizar dentro do dever de proteção ao meio ambiente natural uma interrelação com o dever de proteção integral e prioritária das crianças, ou seja, a proteção do meio ambiente natural,

\footnotetext{
${ }^{3}$ É importante destacar, antes de iniciar a análise durante o trabalho, daquilo que se compreende como meio ambiente natural, qual é a perspectiva socioambiental e filosófico-política que embasará toda a construção racional da presente pesquisa. Desta feita, a perspectiva ambiental que se desenvolve neste trabalho se fará a partir de uma visão múltiplo-dialética da realidade, principalmente, em relação ao meio ambiente natural, objetivando, assim, compreender que a existência humana, animal, vegetal, mineral, está interligada, ou seja, tudo está relacionado e influenciando todas as outras coisas. Essa perspectiva será desenvolvida, por sua vez, a partir do que se convencionou chamar, no contexto latino-americano, de ecocentrismo, fruto de uma ecofosia latino-americana que efetivará o rompimento com a racionalidade antropocêntrica da modernidade iluminista ou, até mesmo, com a perspectiva biocêntrica. Assim, é a partir dessa perspectiva que Estermann apontará que "la ecología o - mejor - ecosofia no es una cuestión de protección ambiental, sino un paradigma holístico de vida y de economía que está en sintonía con las fuerzas y la red de relaciones del cosmos. La concepción andina del universo como organismo considera cualquier deterioro del equilíbrio cósmico como efermidad que se vuelve, en caso del crecimiento ilimitado capitalista, em câncer con metástases generalizadas" (2013, p. 11). Essa compreensão é percebida através do desenvolvimento de alguns princípios que embasam a racionalidade andina, sobretudo, a racionalidade Quéchua, quais sejam: a) o princípio da correspondência - que é a interligação cosmológica entre o micro e o macrocosmos; b) o princípio da complementariedade - que objetiva a necessidade da existência da diversidade e da pluralidade, pois há a percepção de que o ser só será completo na presença do outro ser, que assim como aquele, pertence ao cosmos; c) o princípio da reciprocidade - pelo qual se identifica que cada ato realizado corresponderá, consequentemente, a um ato ou fato que lhe é recíproco, desde o mais simples ao mais gravoso, ou seja, as atitudes tomadas e que desencadeiam determinado fato no Brasil, serão sentidas por todos e em todos os locais do cosmos, reciprocamente, considerado como uma grande teia que liga e arrama todos os seres que existem, pois esse princípio regerá, não só as inter-relações humanas, desencadeadas entre as pessoas ou as sociedades, mas, também, todos os outros tipos de inter-relação, sejam elas entre os seres humanos e a natureza ou o divino, haja vista a ética não se reduzir ao ser humano e seu atuar, possuindo a partir dessas premissas, dimensões cósmicas; d) o princípio da ciclicidade - que diz respeito a possibilidade de se perceber o movimento circular da história, ou seja, a infinidade não é entendida como uma linha sem fim, senão como movimento circular ou espiral interminável, sendo que cada um desses círculos ou espirais pode ser compreendido como as estações do ano, a sucessão de gerações ou as diferentes épocas históricas. Desse modo, nessa perspectiva ecofilosófica andina ecocêntrica todos os seres, interligados, devem cooperar para a existência e salvaguarda da pachamama, o que se dará através de um bien vivir (allin kawsay; suma qamaña; sumak kawsay).
} 
bem como desses sujeitos em desenvolvimento passa por uma educação para a proteção do meio ambiente?

Portanto, tendo os pais o dever de proteger seus filhos integralmente e prioritariamente, bem como o fato de toda a sociedade ter o dever de proteção do meio ambiente natural, o presente trabalho se mostra importante para o debate dos deveres fundamentais, ao passo que trabalha a simbiose desses dois deveres com objetivo de trazer novas teses ao movimento contínuo dos debates científicos.

\section{OS DEVERES FUNDAMENTAIS: A CONSTRUÇÃO MÚLTIPLO-DIALÉTICA ${ }^{4}$ DE UM CONCEITO}

O estudo dos deveres fundamentais não é tarefa fácil, seja pelo fato do constitucionalismo moderno ocidental sempre buscar enaltecer os direitos, seja em decorrência dos poucos estudos sobre o tema, em que pese sua real importância social, política e cultural.

É a partir desse cenário que esse trabalho aborda aspectos gerais acerca da teoria dos deveres fundamentais, buscando contribuir para o desenvolvimento de um entendimento acerca dos deveres fundamentais, sobretudo, deveres inerentes a proteção do meio ambiente natural, bem como da proteção integral e prioritária das crianças - o que será discutido abaixo a partir da relação entre pais e filhos.

Assim, ao analisarmos as construções teóricas acerca dos deveres fundamentais, ou constitucionais, inerentes a um determinado ordenamento jurídico constitucional, percebemos que alguns autores apontam, de um lado, a falta de efeitos jurídicos desses deveres fundamentais constitucionais e, de outro, que tais deveres representariam uma forma de limitação aos limites materiais do poder público.

Neste sentido, aponta Llorente (2001, p. 16) que:

Os enunciados de deveres não têm efeitos jurídicos algum, mas apenas, e se houver, uma função política, embora tampouco haja unanimidade em discernir qual função, se existir alguma, esses enunciados desempenham: para uns, tem, simplesmente, a função de servir de sustento ideológico ao poder, na tentativa de lhe dar uma fundamentação ética; para outros, ao contrário, a função dos deveres, tal como a dos direitos, é a de impor limites materiais a

\footnotetext{
${ }^{4} \mathrm{O}$ paradigma múltiplo-dialético pode ser compreendido desde sua matriz grega, até a contemporaneidade, como o modelo de racionalidade capaz de possibilitar a existência de inúmeras realidades que, mesmo sendo diferentes entre si, convivem em harmonia dentro de uma mesma realidade político-social, ou seja, é o que nos possibilitará perceber a multiplicidade de existência e de modos de compreensão possíveis, bem como a compreensão de que está tudo inter-relacionado, de que tudo o que existe está ligado a ponto de ser especial para a vida em harmonia. É neste sentido que Krohling apontará para o fato de que desde sua formação mais incipiente, na Grécia antiga, a perspectiva do múltiplo dialético ser um importante marco na ascensão e promoção do debate sobre quaisquer situações, o que possibilitará, não só o surgimento, mas a necessidade de sua realização prática, do que hoje chamamos de diferença ou, mais recentemente, de diversidade, pois segundo ele "Os gregos já tinham saído da mitologia, pois viviam a presença de um novo marco, isto é, a realidade da pólis, que modificou profundamente a sua maneira de ser e viver. (...) a ágora (praça pública) é o principal espaço e instrumento de poder. Nesse cenário descendências monárquicas, origens divinas da natureza e explicações mitológicas do poder não têm mais guarida. (...) tudo é debatido. As pessoas agora são iguais. Não há mais hierarquia absoluta e muito menos monarquia. (...). Esse é o marco inicial. Não há nada que não possa ser discutido. Não existem mais verdades eternas (2014, p. 23-24)".
} 
potestade normativa do poder público ${ }^{5}$.

É possível visualizar, a partir de então, que as discussões acerca da configuração jurídica dos deveres fundamentais é campo arenoso, por onde se debruçam incansáveis teorias na tentativa de lhes dar normatividade ou, simplesmente, lhes reconhecer como meros deveres éticos das pessoas enquanto pertencentes ao grupo social que conforma o Estado.

Não são simples divagações ou elucubrações teóricas àquelas vertentes que não percebem nos deveres fundamentais um caráter normativo, mas, tão somente, um dever ético, haja vista o fato de que em suas origens, os deveres fundamentais ou constitucionais, terem surgido de discussões de cunho religioso, moral ou filosófico (MARTINEZ, 1986, p. 329).

A fim de fixar características que nos permitam identificar os deveres fundamentais, destacamos as palavras de Martinez (1986, p. 335), para quem esses deveres fundamentais apresentam três aspectos principais, que podem ser elencados da seguinte forma:

(...) a) o dever jurídico existe com independência de que o dever trabalhado tenha tido previamente, ou não, uma dimensão moral (...); b) o dever jurídico tem que estar reconhecido por uma norma pertencente ao Ordenamento; c) normalmente os deveres jurídicos trazem consigo uma sanção para os casos onde houver o seu inadimplemento (... 6$)^{6}$.

Em que pese à robustez dos citados argumentos, outros há, tão robustos quanto, que disciplinam os deveres fundamentais sob uma visão diferente. Há quem entenda que esses deveres, mesmo que não presentes expressamente em um determinado ordenamento poderão ser reconhecidos como tal, a partir, por exemplo, de uma leitura ampla da norma que regula um determinado direito que, para ser exercitado, necessitará que alguém cumpra um determinado dever.

É o que Valdés (1986b, p. 68), em resposta às críticas de Francisco Laporta e Juan Carlos Bayón, feitas a um artigo que aquele havia publicado acerca dos deveres positivos gerais e sua fundamentação, ressaltará, no sentido de que, para a imposição desses deveres, de um ponto de vista meramente ético, não é necessária a existência do Estado.

Para ele os deveres fundamentais existem, independentemente, da existência de uma codificação estatal sobre sua fundamentação, pois o Estado servirá, tão somente, para assegurar o cumprimento ou sancionar o não cumprimento desses deveres que são inerentes à sociedade humana.

\footnotetext{
${ }^{5}$ No original: "Los enunciados de deberes no tienen efectos jurídico alguno, sino sólo, si acaso, una función política, aunque tampoco hay unanimidad a la hora de discernir cual sea (si alguna), la que estas normas desempeñan: para unos, simplemente la de servir de sustento ideológico al poder, la de intentar dotarlo de una fundamentación ética; para otros, más bien al contrario, la función de los deberes, como la de los derechos, es la de imponer limites materiales a la potestad normativa del poder público" (Tradução nossa).

${ }^{6}$ No original: “(...) a) El deber jurídico existe com independencia de que el deber de que se trata hay a tenido previamente o no una dimensión moral (...); b) El deber jurídico tiene que estar reconocido por una norma perteneciente ao Ordenamiento; c) normalmente los deberes jurídicos llevan a pareja da una sanción en caso de incumplimiento (...)" (Tradução nossa).
} 
Os deveres fundamentais ou constitucionais, neste sentido, conforme se depreende das análises teóricas acima, existem em decorrência de um direito fundamental contrário, ou seja, na medida em que a Constituição, base do Estado, nos assegura uma série de direitos fundamentais, em contrapartida, faz surgir uma série de deveres.

Tal construção hermenêutica é o que pode ser percebido da leitura, por exemplo, do artigo 75 , da Constituição da República Dominicana de 26 de janeiro de $2010^{7}$, responsável por trazer um rol de deveres fundamentais para os dominicanos, que passam a ter uma Constituição que não está, tão somente, repleta de direitos, mas, também, de deveres.

Antes de continuar a discussão é necessário destacar, acerca dos deveres fundamentais, alguns pontos relevantes, tanto em relação às discussões acercada existência, ou não, de deveres positivos gerais, quanto, no caso de haver essa possibilidade, sobre o modo como se daria a contraprestação ao direito, pois todo dever, consequentemente, deverá encampar um direito que lhe é oposto.

Neste ponto, Valdés (1986a, p. 17) qualifica quais seriam esses deveres fundamentais de natureza geral, ou seja, aqueles que todos nós estaríamos obrigados a cumprir, independentemente de mantermos relação direta com aquele que possui o direito de lhe cobrar, expondo, neste sentido, que:

Deveres positivos gerais são aqueles cujo conteúdo é uma ação de assistência ao próximo que requer um sacrifício trivial e cuja existência não depende da identidade do obrigado nem a do(s) destinatário(s) e tampouco é o resultado de algum tipo de relação contratual prévia ${ }^{8}$.

Com isso podemos perceber que por este entendimento quaisquer pessoas poderiam, em estado de necessidade, obrigar quaisquer outros, a lhes ajudar, não devendo essa ajuda ser maior que algo trivial, ou seja, algo que não imponha àquele que presta a ajuda, uma diminuição de suas posses capaz de levá-lo ao status daquele a

\footnotetext{
7 O citado artigo dispõe que: "CAPÍTULO IV - DE LOS DEBERES FUNDAMENTALES - Artículo 75 - Deberes fundamentales. Los derechos fundamentales reconocidos en esta Constitución determinan La existencia de un orden de responsabilidad jurídica y moral, que obliga La conducta del hombre y La mujer en sociedad. En consecuencia, se declaran como deberes fundamentales de las personas los siguientes: 1) Acatar y cumplir la Constitución y las leyes, respetar y obedecer las autoridades establecidas por ellas; 2) Votar, siempre que se este em capacidad legal para hacerlo; 3) Prestar los servicios civiles y militares que la Patria requiera para su defensa y conservación, de conformidad com lo establecido por la ley; 4) Prestar servicios para el desarrollo, exigible a los dominicanos y dominicanas de edades comprendidas entre los dieciséis y veintiún años. Estos servicios podrán ser prestados voluntariamente por los mayores de veintiún años. La ley reglamentará estos servicios; 5) Abstener se de realizar todo acto perjudicial a la estabilidad, independencia o soberanía de la República Dominicana; 6) Tributar, de acuerdo con la ley y en proporción a su capacidad contributiva, para financiar los gastos e inversiones públicas. Es deber fundamental del Estado garantizar La racionalidad del gasto público y La promoción de una administración pública eficiente; 7) Dedicar se a um trabajo digno, de suelección, a fin de proveer el sustento propio y el de su familia para alcanzar El perfeccionamiento de su personalidad y contribuir al bien estar y progreso de La sociedad; 8) Asistir a los establecimientos educativos de la Nación para recibir, conforme lo dispone esta Constitución, La educación obligatoria; 9) Cooperar con el Estado encuanto a La asistencia y seguridad social, de acuerdo con sus posibilidades; 10) Actuar conforme al principio de solidaridad social, respondiendo com acciones humanitarias ante situaciones de calamidad pública o que pongan en peligro la vida o La salud de las personas; 11) Desarrollar y difundir la cultura dominicana y proteger los recursos naturales del país, garantizando La conservación de un ambiente limpio y sano; 12) Velar por El fortalecimiento y La calidad de la democracia, El respeto Del patrimonio público y El ejercicio transparente de La función pública".

${ }^{8}$ No original: "Deberes positivos general es son aquéllos cuyo contenido es una acción de assistência al prójimo que requiere un sacrifício trivial y cuya existencia no depende de la identidad del obligado ni de la del (o de los) destinatário (s) y tampoco es el resultado de algún tipo de relación contractual previa" (Tradução nossa).
} 
quem ajuda (VALDÉS, 1986a, p. 25).

Entretanto, existem posições diversas a essa, principalmente no tocante a possibilidade, ou não, da construção de um entendimento acerca dos deveres fundamentais, reconhecendo-os como positivos e gerais, conforme se depreende em Laporta (1986) e Bayón (1986) - ambos criticam, conforme se aludiu acima, as noções trazidas por Valdés (1986a) no tocante às discussões em destaque.

Laporta (1986, p. 55) apresenta suas divergências à Valdés, em relação àquilo que esse chama de deveres positivos gerais, no ponto acerca da responsabilidade pela omissão, ou seja, Laporta traz entendimento de que se levarmos às propostas de Valdés às últimas consequências, as regras acerca da responsabilidade em decorrência de um inadimplemento de uma obrigação restariam inócuas.

Ele chega a essa conclusão, tendo em vista que sendo os deveres gerais, àqueles que tivessem, em contrapartida, direitos, poderiam escolher, dentre um universo de obrigados, àquele que lhe aprouvesse, o que retiraria toda e qualquer segurança jurídica dos processos judiciais, sendo que, aquele que tem direito frente a um coletivo de pessoas, frente a outras, possui o mesmo dever.

De outro lado, Bayón (1986) aponta críticas à postura de Valdés no tocante aos limites impostos a esses deveres positivos gerais que todos teríamos, destacando, especificamente, o critério da trivialidade entabulado por Valdés para limitar as obrigações, ou seja, os deveres dos indivíduos para com aqueles que lhes são comuns em uma sociedade.

Bayón (1986, p. 46) destacará, neste sentido, que “(...) o altruísmo mínimo, baseado na ideia de sacrifício trivial, parece que não nos serve (...). se alguém tem em seu poder recursos em abundância - sendo que frente a esses um terceiro tem direito - deve entregá-los em sua totalidade, não uma parte <<trivial >> dos mesmos ${ }^{9 ”}$, ou seja, para ele a trivialidade como sendo o elemento de limite ao quantum do dever, não corresponde ao melhor parâmetro.

Em que pesem as discussões sobre as características inerentes aos deveres fundamentais, o importante é saber que se trata de um campo ainda em conhecimento, onde não há verdades absolutas, mas, pelo contrário, inúmeras possibilidades, o que corrobora a necessidade de uma metodologia múltiplo-dialética.

Objetivando uma dessas possibilidades, o Grupo de Pesquisa Estado, Democracia Constitucional e Direitos Fundamentais, do Programa de Pós Graduação Stritu Sensu da Faculdade de Direito de Vitória, através de seus membros, entabulou um conceito para os Deveres Fundamentais, a fim de fixar um posicionamento acerca do tema, definindo dever fundamental como uma categoria jurídico-constitucional, fundada na solidariedade, que impóe condutas proporcionais àqueles submetidos a uma determinada ordem democrática,

\footnotetext{
${ }^{9}$ No original: “(...) el altruísmo mínimo, basado em la idea de sacrificio trivial, parece que no nos lo brinda. (...) si alguien tiene em su poder recursos sin título alguno - y a los cuales tiene direcho um tercero - debe entregarlos em su totalidad, no uma parte <<trivial >> de los mismos". (Tradução Nossa).
} 
passíveis ou não de sanção, com a finalidade de promoção de direitos fundamentais ${ }^{10}$.

A partir daí, não restam dúvidas de que existe um dever fundamental, tanto em relação a necessidade de salvaguarda e efetivação de uma proteção ao meio ambiente natural - direito de todos -, bem como frente a proteção integral e prioritária das crianças - restrita aqui a atuação dos pais enquanto primeiro contato das crianças com os padrões de conduta dos indivíduos de um Estado.

Esses deveres fundamentais, portanto, como se debate neste trabalho, se inter-relacionam, pois um dos mecanismos de proteção ao meio ambiente natural é a prática de uma formação humana para esse fim, o que pode ser conseguido com a atuação dos pais durante o desenvolvimento de seus filhos.

A proteção integral e prioritária das crianças passará, sobretudo, pela preservação de um meio ambiente natural, equilibrando a partir das necessidades das presentes e futuras gerações, o que será melhor debatido nos próximos tópicos deste trabalho onde se desenvolverá melhor as ideias inerentes aos deveres fundamentais de proteção ao meio ambiente natural, bem como às crianças.

\section{O DEVER FUNDAMENTAL DE PROTEÇÃO AO MEIO AMBIENTE NATURAL ${ }^{11}$}

A preocupação com o Meio Ambiente no ordenamento jurídico brasileiro data de muito antes do Brasil existir como um país independente, ou seja, as Ordenações Filipinas, já previam em seu Livro Quinto, Título LXXV, uma pena gravíssima àquele que cortasse, indevidamente, árvore ou fruto, estando o sujeito às penas de açoite e ao degredo para a África pelo prazo de quatro anos, nos casos de danos mínimos, ou perpetuamente, se o dano fosse de natureza grave ${ }^{12}$.

Contudo, em que pesem as primeiras preocupações em nosso território datarem do período colonial, foi só com a Constituição de 1988 que o Meio Ambiente passou a ser disposto, constitucionalmente, em capítulo

\footnotetext{
${ }^{10}$ Conceito construído coletivamente pelos membros do grupo de pesquisa Estado, Democracia Constitucional e Direitos Fundamentais, no $1^{\circ}$ semestre de 2013, coordenado pelos professores Dr. Daury Cesar Fabriz e Dr. Adriano Sant'Ana Pedra, do Programa de Pós-Graduação Stricto Sensu - Mestrado e Doutorado - em Direitos e Garantias Fundamentais da Faculdade de Direito de Vitória (FDV). Para maiores informações sobre as discussões de onde extraiu-se o conceito destacado acima, ver GONÇALVES, Luísa Cortat Simonetti e FABRIZ, Daury Cesar. Dever Fundamental: a construção de um conceito. In. DE MARCO, Christian Magnus e OUTROS. Direitos Fundamentais Civis: teoria geral e mecanismos de efetividade no Brasil e na Espanha. Tomo I. Joaçaba: Editora UNOESC, 2013.p. 87-96.

11 "O meio ambiente natural é aquele constituído por solo, água, ar atmosférico, flora e fauna. Concentra o fenômeno da homeostase, consistente no equilíbrio dinâmico entre os seres vivos e o meio em que vivem” (FIORILLO, Celso Antônio Pacheco. Curso de Direito Ambiental Brasileiro. São Paulo: Saraiva. 2000, p. 19). A partir de então, cabe destacar que o termo meio ambiente fora inserido no ordenamento jurídico brasileiro considerando não só seu aspecto cotidiano, pois a expressão foi incorporada de forma ampla a partir da Constituição Federativa do Brasil de 1988 - Art. 20, III, IV, V, VI, X; Art. 23, inc. VII; Art. 24, VI; Art. 26, III; Art. 216, V e Art. 225, $\$ 1^{\circ}$, III, $\$ 4^{\circ}$, todos do referido diploma constitucional -, bem como pelas leis infraconstitucionais, conforme destaca Leite (1998. p. 51), como, por exemplo, as determinações do art. 3º, inciso I, da lei no. 6.938/81 que dispõe sobre a Política Nacional do Meio Ambiente, definindo meio ambiente como "(...) o conjunto de condições, influências e interações de ordem física, química e biológica, que permite, abriga e rege a vida em todas as suas formas".

${ }^{12}$ FEDERAL, Supremo Tribunal. Inquérito n. 870-2/RJ. 1996. p. 11-462 apud MORAES, Alexandre de. Direito Constitucional. $21^{\text {a }}$ ed. ampl. até EC/53 de 19 de Dezembro de 2006. São Paulo: Atlas, 2007. p. 795.
} 
próprio dentro das normas constitucionais do Texto Maior.

A respeito desse ponto, Milaré aponta que a Constituição Federal de 1988 pode ser visto como “(...) marco histórico de inegável valor, dado que as Constituições que precederam a de 1988 jamais se preocuparam da proteção do meio ambiente de forma específica e global. Nelas sequer uma vez foi empregada a expressão 'meio ambiente', a revelar total despreocupação com o próprio espaço em que vivemos ${ }^{13}$.

A Carta Constitucional de 1988, portanto, surge a partir de um momento em que os países, regra geral, começam a discutir as questões ambientais com maior seriedade, percebendo, a partir de dados climáticos de pesquisas científicas sobre as mudanças do clima, um futuro preocupante para as próximas gerações que nada fosse feito.

Nos termos da Declaração sobre o Ambiente Humano, concretizada durante a Conferência das Nações Unidas em Estocolmo na Suécia em 1972, quando os países, ali reunidos - dentre os quais o Brasil -proclamaram

O homem tem o direito fundamental à liberdade, à igualdade e ao desfrute de condições de vida adequadas, em um meio ambiente de qualidade tal que the permite levar uma vida digna, gozar de bem-estar e é portador solene de obrigação de proteger e melhorar o meio ambiente, para as gerações presentes e futuras. A esse respeito, as políticas que promovem ou perpetuam o 'apartheid', a segregação racial, a discriminação, a opressão colonial e outras formas de opressão e de dominação estrangeira permanecem condenadas e devem ser eliminadas. Os recursos naturais da Terra, incluídos o ar, a água, o solo, a flora e a fauna e, especialmente, parcelas representativas dos ecossistemas naturais, devem ser preservados em benefício das gerações atuais e futuras, mediante um cuidadoso planejamento ou administração adequados. Deve ser mantida e, sempre que possível, restaurada ou melhorada a capacidade da Terra de produzir recursos renováveis vitais. O homem tem a responsabilidade especial de preservar e administrar judiciosamente o patrimônio representado pela fauna e flora silvestres, bem assim o seu habitat, que se encontram atualmente em grave perigo, por uma combinação de fatores adversos. Em conseqüência, ao planificar o desenvolvimento econômico, dever ser atribuída importância à conservação da natureza, incluídas a flora e a fauna silvestres ${ }^{14}$.

A Constituição Federal de 1988, a partir dessa visão sobre o meio ambiente ${ }^{15}$, consubstanciada por documentos internacionais que foram surgindo, principalmente, a partir da segunda metade do século passado, determinou a proteção do meio ambiente - um direito fundamental de todos os brasileiros - como um dever do Poder Público, da sociedade e de cada um do povo.

\footnotetext{
${ }^{13}$ MILARÉ, Édis. Legislação Ambiental do Brasil. São Paulo: APMP, 1991.p. 3.

${ }^{14}$ ONU, Declaração Sobre Ambiente Humano, 1972, Preâmbulo - Tradução Nossa.

${ }^{15}$ Essa característica internacional dos debates sobre o meio ambiente natural é que possibilita a visualização de uma evolução em conceitos tradicionais como a soberania, o direito de propriedade, o interesse público e privado, o que, para Guido Fernando Silva Soares “(...) no fundo, o meio ambiente é um conceito que desconhece os fenômenos das fronteiras, realidades essas que foram determinadas por critérios históricos e políticos, e que se expressam em definições jurídicas de delimitações dos espaços do Universo, denominadas fronteiras. Na verdade, ventos e correntes marítimas não respeitam linhas divisórias fixadas em terra ou nos espaços aquáticos ou aéreos, por critérios humanos, nem as aves migratórias ou os habitantes dos mares e oceanos necessitam de passaportes para atravessar fronteiras, as quais foram delimitadas, em função dos homens" (2001, p. 298 e 299 ).
} 
O art. 225, caput, do citado Texto Constitucional de 1988, neste sentido, assevera que todos têm direito ao meio ambiente, sendo esse, um ambiente ecologicamente equilibrado ${ }^{16}$, algo essencial à sadia qualidade de vida. Para tanto, impõe ao “(...) Poder Público e à coletividade o dever de defendê-lo e preservá-lo para as presentes e futuras gerações".

Diante dessas premissas, é possível perceber que tanto a efetivação dos direitos humanos, tão necessária para a melhoria da vida em sociedade, principalmente no tocante ao direito à vida em um ambiente ecologicamente equilibrado, bem como o direito ao desenvolvimento sustentável daí decorrente, representam uma das maiores buscas da humanidade ${ }^{17}$ do pós Segunda Guerra Mundial.

Ademais, é importante destacar que, ao realizar uma análise do comportamento humano a partir dessas discussões sobre o meio ambiente que desabrocharam, como visto, com maior regularidade na segunda metade do século passado, Lipovetsky chega a conclusão de que “(...) a ideia de que a Terra está em perigo de morte, impôs uma nova dimensão de responsabilidade, uma concepção inédita das obrigações humanas que ultrapassa a ética tradicional, circunscrita às relações inter-humanas imediatas (1994, p. 244)”.

Portanto, “(...) tanto os direitos como os deveres fundamentais integram o estatuto constitucional do indivíduo, ou melhor (...) da pessoa", de modo que ao se falar de direitos fundamentais das pessoas, tais como o meio ambiente ecologicamente equilibrado nos termos do art. 225, da CF/88, necessariamente deve-se lembrar da existência, concomitante, de deveres fundamentais necessários à essa concretização (NABAIS, 2007, p. 164).

Por mais liberal que possa ser um Estado, do momento que se constitui como tal, parcela da liberdade dos cidadãos fatalmente será perdida, em prol do surgimento desse ente coletivo chamado Estado, o que é conhecido na teoria geral do estado, como contrato social.

Os indivíduos, neste diapasão, adquirirão inúmeras responsabilidades perante toda a coletividade da qual fazem parte, dentre as quais, se destacam algumas obrigações de cunho constitucional, que podem ou não estar previstas no texto da constituição do Estado, percebidas aqui como deveres fundamentais.

\footnotetext{
${ }^{16}$ Para conseguir analisar a ideia por traz de um meio ambiente ecologicamente equilibrado, o Direito necessita aliar conhecimentos de outras áreas, tais como: a Ecologia, a Biologia, a Geografia, dentre outras. É a Ecologia, por exemplo, a responsável por conceituar biosfera como sendo o conjunto do solo, da água e do ar existentes no Planeta Terra, elementos indispensáveis à vida, principalmente, a do Homem. Mas, mesmo no Direito, há uma distribuição entre os vários ramos de seu conhecimento para debater sobre o meio ambiente. A proteção, portanto, nos termos postos na Constituição de 1988, é uma simbiose entre o Direito Constitucional, o Direito Ambiental, o Direito Internacional, o Direito Civil, o Direito Administrativo, entre outros.

${ }^{17}$ Sobre tais apontamentos Cançado Trindade (1993, p. 145) destaca ser importante que se considere "para os desenvolvimentos futuros dos mecanismos de proteção internacional da pessoa humana e do meio ambiente a questão de sua proteção erga omnes. Os distintos instrumentos de proteção internacional dos direitos humanos e do meio ambiente incorporam obrigações de conteúdo e alcance variáveis: algumas normas são suscetíveis de aplicabilidade direta, outras afiguram-se antes como programáticas. Há, pois, que prestar atenção à natureza jurídica das obrigações. A esse respeito surge precisamente a questão da proteção erga omnes de determinados direitos garantidos, que levanta o ponto da aplicabilidade a terceiros - simples particulares ou grupos de particulares - de disposições convencionais (denominado “Drittwirkung” na bibliografia jurídica alemã)”.
} 
Partindo daí, os deveres fundamentais devem ser vistos como situações que se relacionam com matérias relevantes para a sociedade, cujos proveitos decorrentes de seu cumprimento extrapolarão os limites do individual, pois toda a coletividade será beneficiada, direta ou indiretamente, com o regular exercício desses deveres fundamentais, o que, via de consequência, acaba por fortalecer, ainda mais, o Estado Democrático de Direito.

Neste sentido, também é o entendimento de Peces-Barba Martínez, para quem:

O exercício de um dever fundamental não traz benefícios exclusivamente ao titular do direito subjetivo correlato, quando existe, mas alcança uma dimensão de utilidade geral, beneficiando ao conjunto de cidadãos e a sua representação jurídica, o Estado ${ }^{18}$ (1987, p. 336 - tradução nossa).

Assim, ao se tratar do dever fundamental de proteção do meio ambiente natural, uma questão inerentemente de direito fundamental de cariz difuso, é evidente que os benefícios atingirão toda a sociedade. E mais, beneficiará uma sociedade composta não apenas pelas gerações do presente, mas, sobretudo, pelas gerações futuras.

A proteção do meio ambiente a partir da análise do dever fundamental trazido pelo Texto Constitucional de 1988, portanto, extrapolará os limites temporais e físicos, ao passo que a tutela ambiental constitucionalizada em 1988, visou garantir a qualidade de vida dos seres humanos que ainda não existem fisicamente no planeta, o que demonstra o caráter positivo que o dever de proteção do ambiente natural gera, dentre outras coisas, frente a relação humana intergeracional.

Por fim, esse dever fundamental de proteção ao meio ambiente natural apresenta, como se perceberá abaixo, relação com outro importante dever fundamental trazido na Constituição Federal de 1988 - o dever de proteção integral e prioritária das crianças - de modo que juntos, simbioticamente, representam importante avanço para o debate sobre uma educação ambiental que proteja o meio ambiente e, via de consequências, as gerações presentes e futuras.

\section{O DIREITO FUNDAMENTAL DE PROTEÇÃO INTEGRAL E PRIORITÁRIA ÀS CRIANÇAS E O DEVER FUNDAMENTAL DOS PAIS EM REALIZÁ-LO}

A Constituição Federal de 1988 estabeleceu a família como à célula mãe da sociedade ${ }^{19}$. Contudo, isso não quis dizer que às famílias foram garantidos somente direitos, pois o constituinte a incumbiu, dentre outras coisas, de velar pela proteção das crianças, dos adolescentes e jovens, o que se dará, inclusive, de forma integral e prioritária.

\footnotetext{
${ }^{18}$ No original: "El ejercicio de um dever fundamental no reporta beneficios exclusivamente al titular del derecho subjetivo correlativo, cuando existe, sino que alcanza una dimensión de utilidad general, beneficiando al conjunto de los ciudadanos y a su representación jurídica, el Estado".

${ }^{19}$ É o que podemos perceber ao lermos o art. 226, da CR/88, que determina a família como a base da sociedade, tendo, inclusive, uma proteção especial pelo Estado, senão veja: "A família, base da sociedade, tem especial proteção do Estado"
} 
Uma responsabilidade, um dever, que a família divide com a sociedade e com o Estado, conforme determina o art. 227, da Constituição da República de 1988 (CR/88), que assim determina:

É dever da família, da sociedade e do Estado assegurar à criança, ao adolescente e ao jovem, com absoluta prioridade, o direito à vida, à saúde, à alimentação, à educação, ao lazer, à profissionalização, à cultura, à dignidade, ao respeito, à liberdade e à convivência familiar e comunitária, além de colocá-los a salvo de toda forma de negligência, discriminação, exploração violência, crueldade e opressão (Grifos Nossos).

Ressalta-se, conforme delimitado na introdução acima, o presente estudo visa abordar a questão do dever da família em dar proteção integral às crianças a partir de sua relação com seus pais, em que pese o art. 227, da $\mathrm{CR} / 88$, não fazer essa restrição.

Mas quem são as crianças de que fala o citado dispositivo constitucional? Segundo o art. $2^{0^{20}}$, da Lei 8.069/90 - conhecida como Estatuto da Criança e do Adolescente - são consideradas crianças pessoas que tenham até 12 anos de idade incompletos.

Assim, para o estudo pretendido aqui, a análise feita do direito fundamental a proteção integral e prioritária, bem como do dever fundamental em assegurar e concretizar esse direito delimitado na atuação paterna, se dará somente em relação às crianças delimitadas acima.

A partir de então, é possível destacar como a legislação especializada - Lei 8.069/90 - assegura direitos a essas crianças, é o que pode ser visto nos termos do art. $3^{\circ}$, da citada legislação, que determina

A criança e o adolescente gozam de todos os direitos fundamentais inerentes à pessoa humana, sem prejuízo da proteção integral de que trata esta Lei, assegurando-se-lhes, por lei ou por outros meios, todas as oportunidades e facilidades, a fim de lhes facultar o desenvolvimento físico, mental, moral, espiritual e social, em condições de liberdade e de dignidade (Grifos Nossos).

É possível, portanto, visualizar a existência de um Direito Fundamental dessas crianças que, além de uma proteção integral e prioritária, objetiva assegurá-las um desenvolvimento físico, mental, moral e social em condições de liberdade e dignidade, o que, necessariamente, deverá passar por um meio ambiente natural equilibrado e saudável.

Esse aspecto da proteção ao desenvolvimento com liberdade e dignidade das crianças está ligado ao princípio constitucional da paternidade responsável, pois se a CR/88 assegura o livre planejamento familiar, também determina que esse planejamento seja responsável ${ }^{21}$.

Não há como não se reconhecer, neste sentido, a existência de um direito fundamental das crianças em se desenvolver de forma saudável, sendo que esse desenvolvimento passará por uma educação plural, que além

\footnotetext{
${ }^{20}$ Segundo aludido dispositivo infraconstitucional, "Considera-se criança, para os efeitos desta Lei, a pessoa até doze anos de idade incompletos, e adolescente aquela entre doze e dezoito anos de idade".

${ }^{21}$ Sobre esse ponto, o $\$ 7^{\circ}$, do art. 226, da CR/88 determina que "Fundado nos princípios da dignidade da pessoa humana e da paternidade responsável, o planejamento familiar é livre decisão do casal, competindo ao Estado propiciar recursos educacionais e científicos para o exercício desse direito, vedada qualquer forma coercitiva por parte de instituições oficiais ou privadas" (Grifos Nossos).
} 
das disciplinas básicas escolares, compreende uma atuação paterna constante, sobretudo em relação à educação socioambiental.

As crianças, como verdadeiras prioridades, cuja proteção deve vir primeiro que qualquer outra situação, conforme determina o art. $4^{\circ}$, da Lei 8.069/9022, também são agentes importantes para a preservação do meio ambiente natural, pois, enquanto parcela expressiva da sociedade, também possuem o dever de proteção ao meio ambiente.

Neste sentido, o art. 5o, da mesma legislação infraconstitucional acima, assegura que nenhuma criança será objeto de qualquer forma de negligência, discriminação, exploração, violência, crueldade e opressão, sendo, punidas as pessoas que, por ação ou omissão, violarem seus direitos fundamentais, mesmo que essas pessoas sejam seus pais.

Caberá além do Estado e da Sociedade, aos pais (enquanto família) - que em regra compõem o primeiro contato social do desenvolvimento humano das crianças - garantir a concretização de seu direito fundamental à proteção integral e prioritária, pois em sua relação paterno-filial, os pais têm o dever fundamental de garantir citado direito.

Por fim, sobre o dever fundamental dos pais é preciso destacar o fato de que a Constituição Federal de 1988 completará, no próximo dia 05 de Outubro de 2014, 26 anos de existência.

Durante todos esses anos não são inegáveis as inúmeras conquistas alcançadas. Inúmeros foram os direitos que passaram a figurar como esteios sociais. Os princípios ganharam força em detrimento às regras. $\mathrm{O}$ Brasil, a partir de então, renasceu de um sono profundo.

Em que pese hoje já haverem discussões sobre a efetividade ou não dessas conquistas, ou seja, frente a sua concretização, sua realização no mundo da vida, é sabido que os Direitos das Crianças, Adolescentes e Jovens, trazidos pela Constituição Federal de 1988 como integrais e prioritários, representaram - e ainda representam um enorme avanço para a proteção das gerações que surgem e que por ventura surgirão.

\section{A EDUCAÇÃO AMBIENTAL DOS FILHOS COMO DEVER FUNDAMENTAL DOS PAIS: UM MECANISMO DE PRESERVAÇÃO DO MEIO AMBIENTE NATURAL E PROTEÇÃO INTEGRAL E PRIORITÁRIA DAS CRIANÇAS}

Após termos debatido acima as teorias e percepções acerca dos deveres fundamentais, bem como o conceito desenvolvido no âmbito do Grupo de Pesquisa Estado, Democracia e Direitos Fundamentais, do Programa de Pós Graduação Strictu Sensu - Doutorado - da Faculdade de Direito de Vitória (FDV), e a

\footnotetext{
${ }^{22}$ Segundo o citado artigo "É dever da família, da comunidade, da sociedade em geral e do poder público assegurar, com absoluta prioridade, a efetivação dos direitos referentes à vida, à saúde, à alimentação, à educação, ao esporte, ao lazer, à profissionalização, à cultura, à dignidade, ao respeito, à liberdade e à convivência familiar e comunitária".
} 
necessidade de percebermos, a partir daí, a existência de um dever fundamental de proteção ao meio ambiente natural, bem como tendo analisado a questão do direito fundamental a proteção integral e prioritária que a $\mathrm{CF} / 88$ assegura às crianças, a partir de seu art. 227, neste ponto buscaremos compreender como o dever fundamental de proteção ao meio ambiente natural pode ser percebido em uma intrínseca relação com o dever, a cargo dos pais, de proteção integral e prioritária das crianças.

É daí, portanto, que buscaremos analisar como a educação ambiental - entendida aqui como um importante instrumento de formação de sujeitos ambientalmente responsáveis - pode ser compreendida como uma "etapa" do amadurecimento político, social, econômico e, sobretudo, cultural, da criança, a ser realizada, dentre outros atores, especialmente por seus pais, que formam o primeiro núcleo social de contato com as regras e padrões de conduta dos seres humanos em sociedade.

Contudo, é importante destacarmos neste sentido, que a ideia de educação desenvolvida neste trabalho, aparece num sentido muito além daquele identificado a partir da educação escolar, ou seja, não se discute aqui, portanto, o dever dos pais em proporcionar, tão somente, um conhecimento científico-teórico - aquele aprendido, entre outros, nos bancos das escolas - mas, de outro lado, busca-se compreender essa educação como um conjunto de atitudes que compreenderão um modo de ensinamento para a vida.

Assim, a educação ambiental da qual falamos aqui, bem como em todo o decorrer deste trabalho, diz respeito a um processo social, político, econômico, cultural, de amadurecimento do ser humano frente ao meio em que vive, de onde a atuação dos pais, enquanto núcleo social primordial de formação da personalidade do ser humano, é essencial para a formação de um indivíduo que, para além de conhecimentos técnicos-científicos, saberá, por exemplo, qual a importância, para as presentes e futuras gerações, de tomarmos conta do meio ambiente natural, percebendo-o como local no qual nossa existência enquanto seres vivos é possível.

A partir de então é possível compreendermos que não se trata de impor aos pais obrigações que extrapolarão suas forças, pois se tratássemos de educação ambiental num prisma educacional técnico-científico, extaríamos exigindo, através do dever fundamental, uma obrigação a esses pais que seria, na grande maioria das famílias brasileiras, desproporcional.

Não é esse, portanto, o objetivo da presente pesquisa, de modo que por educação ambiental, como discutido acima, compreendemos atitudes praticadas pelos pais em relação aos seus filhos que os ajudarão a se formar como seres humanos ambientalmente mais responsáveis, tais como, por exemplo, o simples fato de se ensinar uma criança a não jogar lixo no chão ou a recolher, após o uso, as embalagens daquilo que acabou de consumir, entre outros. 
Assim, conforme a Política Nacional de Educação Ambiental acentua - Lei n. 9.795/1999²3, art. 1º - é possível compreendermos que a educação ambiental abrangerá todos “(...) os processos por meio dos quais o indivíduo e a coletividade constroem valores sociais, conhecimentos, habilidades, atitudes e competências voltadas para a conservação do meio ambiente (...)", identificado como um bem de uso comum do povo, e necessário, haja vista essencial, à sadia qualidade de vida e sua sustentabilidade.

Esse processo de construção social de habilidades, atitudes, valores sociais, portanto, não dependem de um processo de ensino-aprendizagem que se realiza, sobretudo, nos bancos da escola, mas, ao contrário, está mais inserido do cotidiano das pessoas, em suas relaçães sociais, políticas, econômicas e culturais, de onde a relação dos pais e seus filhos surge como um importante local de amadurecimento de todos esses aspectos sob os quais erigese a educação ambiental tal como trabalhada aqui.

A educação ambiental diante dessas premissas pode ser percebida como um dever, contido no art. 225, $\$ 1^{\circ}$, VI, da CF/88, combinado com a Lei da Política Nacional de Meio Ambiente (Lei n. 6.938/81), bem como de sua regulação específica, através da disciplina da Política da Educação Ambiental da Lei n. 9.795/99.

Nestes termos, a educação ambiental deverá se fazer presente no que poderíamos compreender como esfera formal de sua realização, qual seja, o ensino público e privado, realizando-se de modo transversal - ou seja, estando, de certa forma, inserida no contexto metodológico-pedagógico em todas as disciplinas do currículo bem como de modo específico, através de disciplinas, dentro do currículo, próprias para o ensino aprendizagem ínsito a educação ambiental.

Mas, também, no que poderíamos chamar de educação informal, a ser realizada, por exemplo, nas empresas, organizações sociais, na comunicação - aí incluídos o rádio, os jornais, as revistas, a TV (aberta e fechada), a internet, os órgãos e as instituições públicas, etc. - e, sobretudo, o seio familiar, através da relação entre pais e filhos, em especial frente às crianças que ainda estão nos primeiros anos de suas vidas e ainda em processo de construção de sua personalidade.

A educação ambiental, portanto, deve ser compreendida como um importante instrumento de efetivação da proteção ambiental tanto pelo poder público, quanto pelos particulares, em especial àqueles que possuem como obrigação, um dever fundamental de proteção integral e prioritária de seus filhos, em especial, as crianças.

\footnotetext{
${ }^{23}$ É importante analisarmos essa legislação de forma mais acurada, pois, em que pese dizer respeito a uma determinação normativa para a educação escolar, como vimos acima, conceitua educação ambiental de uma forma aberta, ou seja, um conceito para além dos bancos das escolas, de modo que é importante, neste ponto, destacarmos também que a Lei 9.795/99, que estabelece que a Educação Ambiental deve estar presente, de forma articulada, em todos os níveis e modalidades do processo educativo, deverá ser percebida, enquanto diretriz nacional, a partir de uma análise complementária pelos estabelecimentos de ensino (art. 26, da Lei de Diretrizes e Bases da Educação - 9.394/96) a partir de suas características regionais e locais, conforme preceitua o princípio do 4, VII, da Lei 9.795/99, que valorizará a abordagem articulada das questões ambientais locais, regionais e nacionais, e o artigo $8^{\circ}$, IV e vol.09, no. 04, Rio de Janeiro, 2016. pp. 2373-2389 2386
} 
Por fim, a educação ambiental dos filhos pode ser compreendida como parte do dever fundamental dos pais em thes garantir um crescimento sadio e harmonioso em sociedade, ou seja, um mecanismo de preservação não somente do meio ambiente natural, mas, principalmente, de proteção integral e prioritária das crianças, do presente, bem como, das futuras gerações.

\section{CONSIDERAÇÕES FINAIS: INICIANDO NOVAS DISCUSSÕES}

A proteção do meio ambiente natural, dever de todos, possui como um importante mecanismo para sua efetivação, a promoção de uma educação ambiental, ou seja, promover a orientação de todos e, principalmente, das gerações em desenvolvimento, no sentido de proteção ao meio ambiente natural como mecanismo de salvaguarda da vida humana das presentes e futuras gerações.

Desse modo, é dever dos pais, respectivamente, proporcionar, a partir da proteção integral e prioritária, uma educação ambiental a seus filhos, como instrumento de proteção ao meio ambiente, bem como aos próprios infantes.

Não há como negar a importância do tema em discussão e da controvérsia que gira ao seu entorno, seja ela moral, jurídica, política ou social, pois se por um lado os pais possuem autonomia da vontade que lhes embasam o direito de educar seus filhos livremente - respeitando-se os padrões morais, éticos e de direito impostos pela sociedade -, por outro, possuem o dever de realizar uma paternidade responsável.

Um dever, portanto, a partir dessa paternidade responsável, de proteger integral e prioritariamente seus filhos - sobretudo os que ainda forem crianças - o que, necessariamente, passará, conforme debatido acima, pelo dever fundamental de proteger o meio ambiente natural através de uma educação ambiental - instrumento eficaz para a proteção das presentes e futuras gerações.

O mundo em si já é um local traiçoeiro, que pode ser responsável por circunstâncias que, sem a interferência de ninguém, podem causar danos irreversíveis aos seres humanos, principalmente, àqueles de tenra idade, de modo que caberá aos pais contribuir - através de uma educação ambiental de seus filhos - para a amenização desse preocupante cenário - a depender da análise - moderno, pós ou hipermoderno.

V, da mesma legislação, que incentivam a busca de alternativas curriculares e metodológicas na capacitação da área ambiental e as iniciativas e experiências locais e regionais, incluindo a produção de material educativo. 


\title{
THE NATURAL ENVIRONMENT AND THE INTEGRAL PROTECTION OF CHILDREN: ENVIRONMENTAL EDUCATION AS THE PRIMARY DUTY OF PARENTS FOR THE PRESERVATION OF PRESENT AND FUTURE GENERATIONS
}

\begin{abstract}
The present study aimed at analyzing, among other aspects, the fundamental duties based on an understanding of the concept of fundamental duty, from then on, to develop the analysis of the fundamental duty to protect the natural environment, as well as the duty of parents to provide full and priority protection for their children, especially children, and finally, environmental education as an instrument to fulfill these duties. That is, how environmental education can be understood as part of the fundamental duty of parents in guaranteeing a healthy and harmonious growth in society to their children, thus highlighting as a mechanism of preservation not only of the natural environment, but, mainly, of integral and priority protection of children, of the present, as well as, of future generations.
\end{abstract}

Keywords: Natural Environment; Comprehensive and Priority Protection; Fundamental Duties; Parents; Children.

\section{REFERENCIAS}

BAYÓN, Juan Carlos. Los Deberes Positivos Generales y la Determinación de Sus Límites: observaciones al artículo de Ernesto Garzón Valdés. In: DOXA 3, 1986. p.35-54.

ESTERMANN, Josef. Ecosofía Andina: un paradigma alternativo de convivencia cósmica y de vivir bien. In.: FAIA vol. II, no IX-X. AÑO 2013. Disponível em: <file:///C:/Users/Eleno_lnv/Downloads/DialnetEcosofiaAndina-4714294\%20(1).pdf>. Acessado em 14 de abril de 2015.

La Filosofia Quechua. Disponível em: <http://www.olimon.org/uan/12-quechua-estermann.pdf>. Acessado em 14 de abril de 2015.

FIORILLO, Celso Antônio Pacheco. Curso de Direito Ambiental Brasileiro. São Paulo: Saraiva. 2000.

GONÇALVES, Luísa Cortat Simonetti e FABRIZ, Daury Cesar. Dever Fundamental: a construção de um conceito. In. DE MARCO, Christian Magnus e OUTROS. Direitos Fundamentais Civis: teoria geral e mecanismos de efetividade no Brasil e na Espanha. Tomo I.Joaçaba: Editora UNOESC, 2013.

JIMENEZ, Martha Lucia Olivar. O Estabelecimento de Uma Política Comum de Proteção ao Meio Ambiente: sua necessidade num mercado comum. Estudos de Integração. Brasília: Associação Brasileira de Estudos de Integração do Senado Federal, 1994, v. 7.

KROHLING, Aloísio. Dialética e Direitos Humanos - múltiplo dialético: da Grécia à Contemporaneidade. Curitiba: Juruá Editora, 2014.

LAKATOS, Eva Maria. Metodologia Científica 4aed. rev. e ampl. São Paulo: Editora Atlas, 2004.

LEITE, José Rubens Morato. Introdução ao conceito jurídico de meio ambiente. In: VARELLA, Marcelo Dias; BORGES, Roxana Cardoso Brasileiro (orgs.). O novo em direito ambiental. Belo Horizonte: Del Rey, 1998. 
LIPOVETSKY, Gilles. O Crepúsculo do Dever: a ética indolor dos novos tempos democráticos. Trad. GASPAR, Fátima e GASPAR Carlos. Lisboa: Publicações Dom Quixote, 1994.

LLÓRENTE, Francisco Rubio. Los Deberes Constitucionales. In: Revista Española de Derecho Constitucional. Año 21. Núm. 62. Mayo-agosto 2001.p. 11-56.

MILARÉ, Édis. Legislação Ambiental do Brasil São Paulo: APMP, 1991.

Direito do Ambiente: doutrina, prática, jurisprudência e glossário. 2ªd. rev. atual e ampl. São Paulo: Revista dos Tribunais, 2001.

NABAIS, José Casalta. Por uma liberdade com responsabilidade: estudos sobre direitos e deveres fundamentais. Coimbra: Coimbra Editora, 2007.

PECES-BARBA MARTÍNEZ, Gregorio. Los deberes fundamentales. Doxa. Alicante, n. 04, p. 329-341, 1987. Disponível em: <http://bib.cervantesvirtual.com/servlet/Sirve Obras/12837218659036051876657/cu aderno4/Doxa4_19.pdf>. Acesso em: 15 ago. 2014.

SOARES, Guido Fernando Silva. Direito Internacional do Meio Ambiente. São Paulo: Atlas, 2001. p. 298 e 299.

TRINDADE, Antônio Augusto Cançado. Direitos Humanos e Meio Ambiente: paralelo dos sistemas de proteção internacional. Porto Alegre: Sérgio Antônio Fabris Editor, 1993.

VALDÉS, Ernesto Garzón. Los Deberes Positivos Generales y su Fundamentación. In: DOXA 3, 1986a. p. 17-33. Algunos Comentarios Críticos a Las Críticas de Juan Carlos Bayón y Francisco Laporta. In: DOXA 3, 1986b.p. 65-68.

Trabalho enviado em 11 de dezembro de 2015.

Aceito em 05 de março de 2016. 